\title{
ETNOMÉTODOS Y DECISIÓN JURÍDICA: EL DERECHO ESTATAL COMO VÍA PARA LA CONCRECIÓN DE LOS DERECHOS HUMANOS. UNA PROPUESTA METODOLÓGICA
}

\author{
Artur Stamford da Silva \\ Universidade Federal de Pernambuco. Brasil
}

RESUMEN. ¿Son las normas jurídicas estatales límites para la decisión jurídica a favor de la concreción de los derechos humanos? Nuestra propuesta es que el uso de los textos legales a favor de los derechos humanos es una cuestión valorativa, de interpretación y aplicación de los textos jurídicos. Pensamos que las dificultades no están en los textos "en sí", sino en las personas responsables de aplicar las normas jurídicas estatales. Si es así, el estudio de los etnométodos y de las semánticas sociales propias de la comunidad jurídica, pueden servirnos para comprender la toma de decisiones jurídicas y la posibilidad de que los derechos humanos ganen eficacia a través del uso de los textos legislados.

Palabras clave: Derechos humanos, Etnométodos.

ABSTRACT. Are legal norms issued by the State pursuing the concretion of human rights adequate limits to legal decisions? We consider that whether using legal texts granting human rights is a value concern question: specifically a problem of interpretation and application of those legal texts. Difficulties are not in the text themselves but in the people in charge of the application of those legal norms issued by the State. If this thesis is right then to study the ethnomethods and the social semantics characteristic of the legal communities, could enable us to properly understand legal decisionmaking and the chance for human rights to be more efficacious once they are in legal texts.

Keywords: Human Rights, Etnomethods. 


\begin{abstract}
«Que el mundo va de mal en peor es una queja tan vieja como la propia historia...».
\end{abstract}

(KANT, Immanuel. A Religião Dentro dos Limites da Simples Razão: Os Pensadores, vol. XXV. São Paulo: abril, 1974, 365)

\title{
1. LÍMITES TEÓRICOS Y PRÁCTICOS
}

a convivencia social produce normas y al mismo tiempo conflictos. Esta afirmación no aporta nada nuevo a ningún debate. Tampoco hay novedad en afirmar que los derechos humanos tienen la función de denunciar las explotaciones, la desigualdad, la exclusión social. Con esto apenas llamamos la atención sobre el hecho de que la práctica de vivir en sociedad implica vivir la paradoja del límite: el límite entre el orden, las reivindicaciones y el desorden. La paradoja del límite nos lleva a frases como: hacer la guerra para hacer la paz, imponer la democracia y tantas otras oraciones semejantes. Muchos de los argumentos utilizados por los defensores de los derechos humanos pueden servir a gobiernos democráticos igual que a gobiernos tiránicos y dictatoriales. Nuestra propuesta es cuestionar en qué medida la legalidad estatal puede servir para la defensa de los derechos humanos, principalmente si consideramos que la vida en sociedad crea normas y, al mismo tiempo, estimula el cambio social.

Lo mismo ocurre con los aportes teóricos y sus diversas dicotomías: público y privado, Derecho natural y iuspositivismo, individualismo y colectivismo, objetivismo y subjetivismo, etc. En estos casos estamos hablando de la paradoja del límite. La teoría construye los patrones del pensar y del conocer al mismo tiempo que nos lleva a buscar medios para cambiarlos, para, de esta manera, continuar siendo capaces de explicar la vida en sociedad. Por ejemplo: de un lado están los que abogan porque todo está en la ley (los ontólogos, legalistas y dogmáticos formalistas, como en la Escuela de la Exégesis); del otro lado, los que dicen que el juez primero decide y después recurre a un texto legal para justificar su juicio (nihilismo retórico). Estos dos extremos nos llevan a la paradoja de que tanto los legalistas como los nihilistas abogan por la arbitrariedad como explicación de la decisión jurídica. Los primeros, por la arbitrariedad de la norma jurídica (del texto), y los otros, por la arbitrariedad del juez. Pero eso no deja de ser una más de las dicotomías de la modernidad, llena de engaños y falsos dilemas.

La propuesta es cambiar o, si fuera posible, suprimir el raciocinio causal y las dicotomías. Para eso, una forma de hacerlo es evitar recurrir a clasificaciones pre-formateadas (a priori), evitar los juicios basados en el oí decir, como son las opiniones personales, los argumentos de autoridad. No hay duda de que existen límites. Sin embargo, ¿es posible identificarlos?

En la sociedad actual, según la forma positivista del Derecho, desde la Escuela de la Exégesis y la Jurisprudencia de Conceptos, no se hace ciencia jurídica sino a través de la fórmula de la racionalidad causa-efecto y el método deductivo. Hoy se sabe que las teorías no son suficientes, así como la práctica tampoco lo es, para establecer criterios para las decisiones justas, correctas. No hay fórmula, no hay modelo capaz de servir a todos y para todo indistintamente, pues nada es distinto y nadie es igual. Pero que no haya fórmulas y modelos no significa que debamos adherirnos a la lógica del "todo 
vale". Decir que no hay un modelo perfecto no es lo mismo que defender la inexistencia de parámetros para la toma de decisiones. Más aún, creer en un modelo definitivo no es una paradoja, es un engaño.

Las expresiones «norma jurídica estatal» y «textos legislados» serán tratadas como sinónimas y las dos se refieren a la creación de normas por autoridades jurídicamente competentes para producirlas, o sea, Derecho estatal.

Volviendo a la cuestión del engaño, al mismo tiempo que los derechos son criterios abstractos y generales para las decisiones jurídicas, sufren adaptaciones cuando son usados en las tomas de decisiones. Por eso imaginar un modelo en definitiva es un engaño.

Suponemos que la toma de conciencia de la desigualdad social, así como de sus consecuencias, ya se va dando. Entonces no cabe limitarse al discurso descriptivo de la desigualdad social, es preciso más. Por ello, nuestra pretensión es reflexionar sobre el Derecho como criterio de decisión, sea judicial, sea de los individuos en convivencia social ${ }^{1}$.

Definir criterios es hacer elecciones, o sea, toda norma jurídica podría tener un contenido diverso del establecido; es lo mismo que preguntar: ¿por qué el Derecho dice lo que dice y no otra cosa? ${ }^{2}$. ¿Por qué la mayoría de edad es 18 años en unos países y 21 en otros? En términos de posibilidades sociales, de opciones, podría ser cualquier otra: ninguna, 14 años, 16 años, 21 años, cualquiera. Establecer que la mayoría de edad es 18 años es escoger una dentro de las innúmeras posibilidades en el mundo social. Con eso, cuestionamos si hay diferencia de grado de libertad en la toma de decisión política y en la toma de decisión jurídica, como enseña Hans KELSEN.

Sabemos que la actividad de interpretación, aplicación y comprensión involucra los textos de las normas abstractas, así como las descripciones de los casos concretos y los textos de las jurisprudencias. Si es así, al cuestionar la relación entre la decisión política y la decisión jurídica, preguntamos: ¿quién establece esos criterios? O bien, ¿cómo hablar de derechos humanos como búsqueda de una sociedad más justa? ¿Qué justicia es ésa? ¿Qué criterio de justicia es posible establecer previamente? ¿Cómo considerar una norma jurídica estatal como Derecho injusto?

Una vía es concebir el Derecho como un producto cultural, lo que nos lleva a la visión de que el contenido de sus normas puede cambiar, según cambie el interés político, por ejemplo. El culturalismo nos lleva a la trampa del naturalismo historicista. De todas formas, seguimos creyendo que los textos legislados sirven para evitar el caos social, pero ¿por qué? ¿Por qué nos sentimos incluidos y no excluidos? ¿Por qué nuestras elecciones en la vida no están amenazadas por el Derecho, pero sí por la lógica del mercado? Una razón es porque insistimos en creer que el Derecho es una institución social inmune a los intereses y valores sociales. Con todo, seguimos sabiendo que no existe un mecanismo para impedir que por medio de un golpe de Estado, incluso basado en el cambio de legislación constitucional, sea implementada una dictadura en cualquier país.

Luhmann, N., 2005: El derecho de la sociedad, México: Universidad Iberoamericana; SAMPAIO FerRAZ JR., T., 1998: Função social da dogmática jurídica, São Paulo: Max Limonad.

${ }^{2}$ CORReAS, O., 1995: Crítica da ideologia jurídica. Ensaio sócio-semiológico, Porto Alegre: SAFE, pp. 17-20. 
Otra vía es concebir que del cambio de los jueces en un tribunal resultarán cambios en sus decisiones. En este caso, no hay que hablar de cultura, pero sí admitir que interpretar y aplicar las normas jurídicas estatales es más que hacer elección entre alternativas legislativas. La lectura de los textos legales no se realiza sin la intervención de la visión de mundo del que juzga, pero no se agota en la opinión personal del juez (arbitrariedad aislada, solipsismo judicial); más bien, la opinión del juez está mezclada con la opinión de la comunidad jurídica a la que pertenece. Así, la vía de la interpretación no elimina completamente la posibilidad de que el Derecho estatal pueda ser usado para apoyar decisiones jurídicas a favor de la concreción de los derechos humanos.

Más aún, decir que el Derecho es un producto cultural no basta para verlo como un obstáculo o instrumento de transformación social. Reflexionar sobre la formación de una cultura, de una lengua, sobre cómo se establecen las reglas de convivencia social, ayuda a pensar que el Derecho puede servir como instrumento contra la desigualdad social, pero también puede servir de instrumento de dominación. La cuestión está en que el uso del texto legislado no se agota en el "texto en sí", las personas son quienes lo usan y lo ponen en acción. Por eso el estudio de la semántica social de la comunidad jurídica puede servir para aclarar diversas cuestiones que las teorías de la argumentación no consiguen.

Otro punto es que basarse en frases de efecto como «precisamos unirnos en la solidaridad para luchar contra la explotación de los excluidos», o en denuncias obvias como «la globalización produce más hambre, miseria y pobreza», llevan a la falta de creencia de los derechos humanos, no despiertan ninguna sensibilización. Primero porque la lucha por la paz es un argumento auto-refutable así como la verdad no puede ser encontrada. Por eso consideramos necesario distinguir la paradoja del engaño. Expresándonos de otra forma, el discurso basado en recursos emocionales puede servir para despertar sentimientos de culpa en personas sensibles a esos tipos de discursos, pero no sirve como medio para alcanzar algunas conquistas efectivas a favor de un cambio en la lectura del Derecho. Tampoco ayuda a atraer nuevos adeptos, sino todo lo contrario.

Partiendo de la visión de que no hay cómo legitimar los derechos humanos recogiendo los discursos emotivos, nuestra pretensión es reflexionar sobre posibles caminos hacia la eficacia de esos derechos haciendo uso del Derecho estatal. Por eso, la perspectiva que el lector debe tener en cuenta durante la lectura de este trabajo es que, no habiendo como separar el Derecho de la política, como apartar los juegos de interés, cabe a los llamados «defensores de los derechos humanos» hacer uso de los mecanismos jurídicos ya establecidos. Por medio de la hermenéutica, interpretando, aplicando y comprendiendo los textos legislados a favor de la ideología de los derechos humanos, es posible avanzar en el intento de tornar eficaz derechos humanos como espacio para la inclusión social. Pero ¿interesa a los juristas promover la inclusión social?; o sea, ¿tiene el sistema jurídico función de promover o estimular cambio social?

Concibiendo la modernidad como el período de la racionalidad, en relación con el mundo jurídico, cuando se piensa en garantizar derechos, se deposita en la codificación gran confianza para realizar esta tarea. La lógica es que las normas abstractas y generales son suficientes para resolver cualquier problema social. Ocurre que, tra- 
tándose de la eficacia, no basta tener normas abstractas y generales. De todas formas, plantear la defensa de un derecho ante de los tribunales implica recorrer el camino de los discursos basados en textos legislados. Incluso cuando se habla de justicia, un principio evocado es el principio de la imparcialidad. Max WEBER, por ejemplo, después de distinguir el Derecho garantizado coactivamente (Derecho formal y Derecho informal), apunta como caso límite para el Derecho informal que sus normas sean creadas por quien no las va a aplicar y que su aplicación ocurra de modo personalmente desinteresado, pues en caso contrario no se puede decir que es Derecho, pero sí coacción arbitraria, como hacen los mafiosos y el narcotráfico ${ }^{3}$.

Mucho se habla de crisis, pero, con relación al Derecho, las crisis significan plantear cambios en los antiguos institutos o proponer nuevos institutos jurídicos y procesales (procedimiento electoral; procedimiento legislativo y procedimiento judicial). O sea, para enfrentar las crisis se proponen nuevas reglas, nuevos institutos, reformulaciones en los presupuestos jurídicos, pero no se habla de cambiar la lógica de lo jurídico.

Llegamos hasta tal punto que la lentidud procesal (la estagnación y mal funcionamiento de los institutos jurídicos) sirve para el uso del Derecho estatal en beneficio de los sin tierra. Abogados brasileños que defienden a campesinos (grilheiros) en la región de Araguaia (Tocantins-Brasil) han utilizado esa lentidud y los mecanismos formales de la legislación procesal para mantener a los campesinos en las tierras ${ }^{4}$. El uso de la fuerza física no ayuda a defenderse de decisiones jurídicas que establecen la devolución de la posesión de las tierras a los que tienen el título formal de propiedad, entonces el camino fue impedir la salida de los grilheiros de las tierras recurriendo y usando instrumentos jurídicos como las acciones judiciales cautelares. La experiencia demostró que bastaba dificultar el proceso judicial por el cual el propietario de las tierras tomase pose para que ellos desistiesen de dar continuidad a la acción judicial de reintegración de posesión. Así los grilheiros se mantuvieron en las tierras.

Hay, pues, límites en la visión positivista dogmática. A partir de la idea del Derecho como sistema se supone que el Derecho es separable de la política y, en nombre de la seguridad jurídica y de la certeza del Derecho, las normas jurídicas son pensadas como dogmas, lo que hace creer que las decisiones jurídicas son verdaderas, correctas e indiscutibles. Para ligar estas ideas con nuestros propósitos en esto texto, haré algunas llamadas de atención para evitar más engaños. La primera llamada de atención se refiere a la posibilidad de cambio de la forma y cómo el orden social es establecido. Ni siempre el orden social contó con la forma del Derecho positivo, tal como el proceso de positivación del Derecho se dio de forma diversa en Francia (civil law) y en Inglaterra (common law). Estos datos generan esperanzas de cambio en el orden social moderno, pues siendo el Derecho puesto por medio de la voluntad humana y al ser esta voluntad cambiante, la forma como hoy vivimos el orden social también puede cambiar, o incluso el Derecho puede servir a la inclusión social. Nos interesa, con eso, evidenciar que muchas veces dejamos de usar mecanismos estatales favora-

3 Weber, M., 1996: Economia y sociedad, México, Fondo de Cultura Mexicana, pp. 257-258; Barry, B., 1997: La justicia como imparcialidad, Barcelona: Paidós.

${ }^{4}$ De Alentar Rocha, O., 1989: «O Advogado Popular e o Judiciário», Direito Insurgente II, Anais da II Reunião LAJUP, S.L.: LAJUP, pp. 43-61. 
bles a la concreción de los derechos humanos por causa de una idea preconcebida. Esto ocurre incluso porque estamos tan envueltos en la crítica por la crítica y en señalar defectos del Estado que dejamos de detectar puntos y mecanismos que puedan venir a beneficiar la inclusión social ${ }^{5}$.

La segunda llamada de atención afecta a la cuestión lingüística. El hecho de que no haya una única lectura correcta no significa negar la posibilidad de que haya una lectura equivocada. Aceptar que no haya una única decisión correcta no significa decir que no existan límites a la decisión, ni que no haya decisiones erradas. Esto es una falsa paradoja. Lo peor de todo es que esa falsedad impide que identifiquemos los espacios del Derecho positivo estatal favorables a los derechos humanos, incluso porque el fenómeno social jurídico no se agota en el ordenamiento jurídico estatal. Pensar lo contrario es un engaño. Además, si en los tribunales y juzgados predomina la idea de que el discurso, para ser aceptado como jurídico, debe tener por base las normas jurídicas, ¿por qué no usar los textos legislados en favor de los derechos humanos? Eso no elimina otras posibles vías de reivindicación. Así como hay textos legislados que dificultan la implementación de esta idea, hay textos legislados que la hacen posible. Es, por lo tanto, necesario no confundir: a) única lectura correcta con que cualquier decisión es posible; $b$ ) que haya diversas lecturas posibles con lectura equivocada ${ }^{6}$. Hay límites aunque sea casi imposible identificarlos.

La tercera llamada de atención trata de la imparcialidad y neutralidad. Las normas jurídicas son generales, por eso pueden ser consideradas políticamente neutras. Si es así, como dicen los positivistas dogmáticos del Derecho, entonces las normas jurídicas tanto pueden servir de obstáculo como de mecanismo para el cambio social. Por lo tanto, ¿qué impide una lectura de los textos legales en favor de la ideología de los derechos humanos? Considerando todo el ordenamiento jurídico, quien se opone a una hermenéutica a favor de los ideales de los derechos humanos no es el texto legislado "en sî", sino sus lectores, los agentes jurídicos, los juristas, la comunidad jurídica.

Para no dejar una impresión utópica - típica de las filosofías éticas vacías, porque, para valer o tener sentido, tendrían que no existir seres humanos- nuestra propuesta no ignora la influencia del juego económico y político, el lobby, en las decisiones jurídicas, todo lo contrario, la idea es justamente que al evidenciar que el Derecho es producto de la comunidad jurídica se enfatiza que las normas jurídicas no son el problema, pero sí las personas que utilizan las normas, las aplican, poniéndolas en fun-

\footnotetext{
5 Oliveira, L., 1997: «Os Excluídos 'Existem'? Notas sobre a Elaboração de um novo Conceito», Revista Brasileira de Ciências Sociais, n. 33, ano 12, fev., Minas Gerais: ANPOCS, pp. 49-61.

${ }^{6}$ Sobre la idea de única decisión correcta, ver: ALEXY, R., 2001: Teoria da argumentação jurídica. A teoria do discurso racional como teoria da justificação jurídica, São Paulo: Landy; DwORKIN, R., Los derechos en sério. Sobre más de una decisión posible, la discrecionalidad, ver HART, H., 1984/1961: The concept of law, Oxford: Oxford University, y Kelsen, H., 1987: Teoria pura do direito, São Paulo: Martins Fontes. Sobre la existencia de lectura errada y sobre límites a la interpretación ver: DERRIDA, J., 2002: A escritura e a diferença, São Paulo: Perspectiva; ECO, H., 2004: Interpretação e superinterpretação, São Paulo: Martins Fontes; FAIRCLOUGH, N., 2001: Discurso e mudança social, Brasília: UnB; Possenti, S., 1999: «A lectura errada existe», en BarzotTo, V. H., 1999: Estado da leitura, Campinas: Mercado de Letras, pp. 169-178; VAN DIJK, T. A., 2000: El discurso como estructura y proceso, Barcelona: Gedisa; GARCía AmADO, J. A., 2003: Ensayos de filosofía jurídica, BogotáColombia: Temis; GARCÍA AMADO, J. A., 2000: «La teoría de la argumentación jurídica: logros y carencias», Sobre el razonamiento jurídico, Revista de ciencias sociales, Facultad de Derecho y Ciencias Sociales, Valparaíso-Chile: Universidad de Valparaíso, pp. 103-129.
} 
cionamiento. LUHMANN nos ayuda a entender estas relaciones con su idea de semántica social ${ }^{7}$.

Esas llamas de atención nos permiten ubicar como límites a la arbitrariedad los etnométodos y la semántica social de la comunidad jurídica.

\section{CRITERIOS DE DECISIÓN VERSUS DECISIÓN JUSTA}

Entre los principales argumentos de la corriente del positivismo dogmático está el de que la promesa del Derecho será igual para todos. Asume entonces el Derecho estatal la calidad de medio suficiente para la seguridad de la vida en sociedad. Con esto, el comportamiento social pasa por un proceso de calificación para ser considerado como jurídico; o sea, no todo lo que ocurre en el ambiente social es jurídico. El jurista parte de las normas jurídicas estatales para leer, comprender y cualificar los hechos y fenómenos sociales como jurídicos o no. Nos referimos a la noción de lo jurídicamente relevante o no relevante, conforme, claro está, a lo previamente definido por el Estado. El Derecho, de esta manera, es transformado en un aparato informativo de los criterios admitidos para el comportamiento en la convivencia social, dejando para las personas la tarea de guiar sus comportamientos según los preceptos jurídicos estatales. Es lo que Herbert HART llama el «paraíso de conceptos» de los juristas ${ }^{8}$.

Este proceso se inicia con la formulación de un mundo jurídico alejado del social. No importa el contexto social, sino la norma, los criterios preestablecidos. Con eso, se habla de expectativas de comportamiento, siendo las normas jurídicas estatales las responsables de garantizar estas expectativas, pues permite a toda y cualquier persona conocer sus derechos. Con eso, las personas pasan a ser sujetos de derecho y, por eso, detentan el poder de exigir que se les respete. En caso contrario, se puede recurrir al poder competente (el judicial) exigiendo el mantenimiento o restauración de sus derechos (como se prevé en el art. 5. ${ }^{\circ}$, LIII, de la Constitución Federal Brasileña).

Para la concretización de la seguridad que se promete por medio del Derecho estatal, los presupuestos fundamentales requeridos son: la obligatoriedad de tomar una decisión sobre todos los casos concretos y la necesidad de que la decisión tomada esté basada en alguna norma jurídica estatal ${ }^{9}$. De esta forma, se considera que para cualquier conflicto social existe una norma jurídica estatal capaz de calificarlo jurídicamente.

Este aparato teórico forma la corriente de pensamiento jurídico llamada de legalismo jurídico o de formalismo dogmático. Esta forma de dogmatismo es difundida por diversos autores, ganando fuerza desde el Código Civil francés (1804), hasta los días actuales. Para esta corriente los conflictos sociales deben ser juzgados como lícitos o ilícitos a partir de los criterios establecidos por las normas jurídicas estatales, dando lugar a la formulación de principios como: «nadie será obligado a hacer o dejar de hacer cualquier cosa sino en virtud de la ley» (Constitución Federal Brasileña,

7 Luhmann, 1985: Come è possible l'ordine sociale, Roma/Bari: Laterza; Luhmann, 1983: Struttura della socetà e semantica, Roma/Bari: Laterza; LuHMANn, 2005.

${ }^{8}$ HART, 1984/1961: p. 143.

9 BobBIO, N., 1993: Teoria generale del diritto, Torino: G. Giappichelli, p. 240; VIEHWEG, T., 1997: Tópica y filosofía del derecho, Barcelona: Gedisa, p. 56. 
art. 5. $\left.{ }^{\circ}, \mathrm{II}\right)$, «no hay crimen sin ley anterior que lo defina, ni pena sin previa determinación legal» (Constitución Federal Brasileña, art. 5. ${ }^{\circ}$, XXXIX), «nadie se dispensa de cumplir la ley, alegando que no la conocía» (Ley de Introducción al Código Civil Brasileño, art. 3. ${ }^{\circ}$.

Esos principios pueden llegar a confortar el espíritu humano, pero no tienen sentido si se considera la vida en sociedad. Evidencian innumerables inconsistencias de la perspectiva dogmática legalista. La búsqueda del mundo perfecto no puede implicar que se olvide del mundo concreto - la forma cómo en la convivencia social las cosas son vividas, convividas y establecidas.

El legalismo es un ejemplo del solipsismo teorético. Los autores de la Escuela de la Exégesis creían que la decisión jurídica podía ser producto de la aplicación de los principios de la lógica formal aristotélica. El juez era considerado «boca de la ley», ya que «sólo hay una única decisión correcta» y que la racionalidad jurídica es silogística, y por eso la «decisión judicial es fruto de la verdad». Con eso, los exégetas creían haber apartado el aspecto social del sistema jurídico y, por tanto, la contaminación de lo social en la aplicación de las normas jurídicas estatales. Todo eso para apartar la subjetividad, la influencia de los intereses políticos. Pero lo curioso es que por detrás de todo el movimiento del Código Civil francés estaba nada menos que Napoleón Bonaparte.

La idea de que se puede llegar a la verdad a través de la lógica de la subsunción, aplicando los principios lógicos-formales al Derecho para clasificar un hecho social, es rechazada incluso por KELSEN, al decir que la decisión judicial es un acto de voluntad del órgano de aplicación del Derecho y no un acto de conocimiento. Cuando el juez se encuentra ante más de una opción, entre las ofrecidas por el ordenamiento jurídico estatal, su elección sobre cuál de ellas aplicar al caso concreto no dependerá del método, pues no hay método de interpretación capaz de garantizar la única elección correcta como querían los autores de la teoría tradicional de la interpretación. KELSEN presenta dos argumentos para esta afirmación: el primero es que «el legislador es relativamente mucho más libre en el acto de creación del Derecho que el juez; pero éste también es creador de derecho y también es relativamente libre con respecto de esta función» ${ }^{10}$; el segundo argumento es que «la pregunta de cuál sea la posibilidad "correcta", en el marco del Derecho aplicable, no es — según los supuestos previos - ninguna pregunta dirigida al conocimiento del Derecho positivo, no es una pregunta teórica-jurídica, sino que es un problema político» ${ }^{11}$.

Así, queda evidenciado que las normas jurídicas del Estado no bastan para la toma de decisiones judiciales. Pero ¿en qué otros factores apoyan los juristas sus decisiones?

En el campo de la lingüística se atribuye a la textura abierta del Derecho el espacio abierto a la creación judicial del Derecho. Debido a la vaguedad y a la ambigüedad de los términos, a través de su interpretación la concepción del jurista interfiere en el contenido del texto legislado. Desde esta visión, se recurre a un aporte teórico diverso del legalismo dogmático jurídico en el estudio de la decisión judicial, como lo hizo Herbert HART ${ }^{12}$.

\footnotetext{
10 KELSEN, 1987: p. 351.

11 Kelsen, 1987: p. 353.

12 HaRT, 1984/1961: pp. 121-132.
} 
En el campo de la sociología del Derecho varios movimientos tratan de negar la reducción del Derecho a las normas. Entre estos movimientos están la escuela del Derecho libre con J. H. KirChMANn y H. KANTOROwicK, el Derecho vivo con E. EHRLICH, la escuela de la libre investigación científica con François GÉNY, el solidarismo de L. Duguit; el realismo estadounidense de O. Holmes y R. Pound; el realismo escandinavo con Alf Ross, además de las contribuciones de sociólogos como Max WEBER. Así como los autores de la teoría de la argumentación jurídica como Ronald Dworkin, Robert AleXY, Aulis AARnio y tantos otros.

Apuntar problemas en el Derecho moderno de la positivación del Derecho no es suficiente para alcanzar el debate propuesto, la cuestión versa más bien sobre si la decisión judicial es justa o no. Si el instrumental positivista no atiende a los criterios de justicia, ¿sería entonces justo dejar al libre arbitrio de los magistrados la elección de estos criterios? Esta cuestión trae polémicas como éstas: ¿cómo hacer para unir la seguridad a la justicia? ¿Cómo garantizar decisiones judiciales justas? ¿Hay base para atribuir a una decisión judicial la cualidad de justa? ¿Cómo evaluar una ley como injusta? Si el arbitrio no es aceptable por dar lugar a la dictadura del poder judicial, tampoco reducir el derecho al Estado garantiza justicia a la decisión. Ante este dilema, ¿cómo tratar el tema?

Nuestra pretensión es reflexionar sobre la necesaria inclusión de las normas sociales de la comunidad jurídica como influyentes en las tomas de decisión jurídica, o sea, a los etnométodos jurídicos. Partiendo de la idea que la vida en sociedad produce la construcción de sentidos para esta comunidad, la producción de patrones de conducta añadidos al sentido son los etnométodos. El lobby es un ejemplo de eso. Llamamos la atención sobre el hecho de que el lobby no es necesariamente algo malo, corrupto. Es una estrategia de supervivencia y, como tal, puede servir para todos los gustos, igual que ocurre con los textos legislativos.

Nuestra reflexión propone que para comprender y explicar la decisión jurídica no se puede dejar de considerar los etnométodos de la comunidad jurídica; con otras palabras, nuestra propuesta es incluir en la hermenéutica jurídica los etnométodos y la semántica social. Aunque pueda ser considerada una perspectiva positivista — pues tiene al Derecho estatal como indispensable para dar respaldo y aceptabilidad a la argumentación, fundamento y justificación de las decisiones jurídicas- no se trata de legalismo ni de formalismo jurídico. Nuestra visión del Derecho es positivista o incluso dogmática, pero dogmática crítica. Esta observación metodológica tiene sentido para aclarar que, como dogmática crítica o sociológica de la decisión jurídica, nos interesa estudiar la "vida" que los agentes jurídicos están estableciendo para las normas jurídicas estatales ${ }^{13}$.

En fin, lo que queremos es evidenciar que no basta legislar, no basta la existencia del texto normativo, pues su eficacia y aplicación dependen de la "vida" que la comunidad jurídica establece para los textos normativos, o sea, dependen de la semántica social.

${ }^{13}$ Stamford da Silva, A., 2000: Decisão jurídica: dogmatismo e empirismo, Curitiba: Juruá. 


\section{EL CONTENIDO DE LAS NORMAS JURÍDICAS Y LOS ETNOMÉTODOS DE LA COMUNIDAD JURÍDICA}

Ante la aporía de la autonomía del Derecho estatal como portador de los únicos criterios a la decisión judicial, se coloca en la hermenéutica el centro de la disputa por el poder de definir el contenido (el sentido) de las normas jurídicas estatales. La cuestión es con qué percepción (visión de mundo) los agentes jurídicos están trabajando la aplicabilidad de los textos legislativos.

El problema es que, como todo texto, el Derecho estatal comporta una lectura tan amplia que puede así funcionar como legitimador tanto de un régimen dar estilo dictatorial como de un socialista o de cualquier otro. En relación a los derechos humanos, una forma de explicar esto es considerar que los derechos humanos son un espacio abierto a las denuncias contra la violencia oficial, con el papel de evidenciar cuestiones y puntos oscuros para la búsqueda de una convivencia con más equilibrio social, económico y jurídico ${ }^{14}$.

La cuestión es que, si para unos hay verdad y, por tanto, los lectores deben ser competentes para encontrarla y conocerla para otros, lo máximo que llegaremos a conocer y formular son opiniones. Este debate alude al tema de si hay una elite intelectual desarrollada y capacitada a conocer la verdad ${ }^{15}$.

Con relación a los derechos humanos, la discusión afecta no sólo a la idea de derechos válidos universalmente sino también a la cuestión de los límites de la tolerancia. Temas estos que llevan a la aporía entre el universalismo y el relativismo cultural. Así como la propuesta de llegar a un término medio como la idea de «universalidad tensionada de particularidad», afirma que «hasta el particularismo radical acepta la idea de que para que cada uno pueda defender su particularismo es necesario añadir el universalismo ético, es el respeto de aquello que se precisa para garantizar la existencia de las particularidades culturales» ${ }^{16}$.

Así, ETXEBERRÍA ofrece reflexiones sobre medios no de eliminar los conflictos, sino para proponer una convivencia social entre diferentes culturas. En tiempos en que la cultura oriental está muy cerca y en constante contacto con la cultura occidental, vivimos justamente esta tensión, a pesar de que la forma de colonización actualmente es muy diversa de la colonización de siglos atrás. Lo que produce un desafío más para el Derecho moderno.

Además, una dificultad a la hora de comprender esta idea reside en que en el sentido común predomina el pensar de forma maniquea, como si tuviésemos sólo dos

14 Alexy, R., 1997: Teoría de los derechos fundamentales, Madrid: Centro de Estudios Constitucionales, pp. 40-41; PÉREZ Luño, A. E., 1999: Derechos bumanos, estado de derecho y constitución, Madrid: Tecnos, pp. 24-25.

15 Aristóteles, 1973b: «Dos argumentos sofísticos», Os Pensadores, São Paulo: Abril cultural; ARISTÓTELES, 1988: «Tópicos», Tratados de lógica (Órganon), vol I, Madrid: Gredos; García AmadO, J. A., 1988: Teorías de la tópica jurídica, Madrid: Civitas, pp. 51 y ss.; VIEHWEG, T., 1986: Tópica y jurisprudência, Madrid: Taurus, pp. 37-38; MEYER, M., 1993: Questões de retórica: linguagem, razão e sedução, Lisboa: Edições 70; Reboul, O., 1998: Introdução à retórica, São Paulo: Martins Fontes, p. 18; Platón, 1967: La republica, Madrid: EDFA; BARILLI, R., 1979: Retórica, Lisboa: Presença, pp. 17-20.

16 Etxeberría, X., 1999: «Los Derechos Humanos. Universalidad Tensionada de Particularidad». Los derechos bumanos, camino hacia la paz, Zaragoza: Gobierno de Aragón, p. 90. 
alternativas: opiniones o verdades, sí o no, cierto o errado; o, incluso, haciendo conexiones simplistas sobre causa y efecto. Pensar así significa apartar de la reflexión la vida cotidiana, pues en lo cotidiano no se vive así. Por eso, afirmamos que los intentos de los estudiosos de la retórica no son capaces de explotar datos empíricos sobre la decisión jurídica. Abandonamos este camino y recurrimos a la sociolingüística, a la semántica social y, aún, a la etnometodología. Para estas corrientes teóricas, en la convivencia social del día a día moldeamos de forma constante nuestra visión del mundo ${ }^{17}$, en ella, la noción de lo cierto, lo bueno y lo justo pierde muchas veces sentido ante las circunstancias sociales, del contexto. Esos «modelos» no son inmutables, al contrario, tenemos gran capacidad de moldearlos según una infinidad de factores incluso la situación fáctica.

En otras palabras, las tomas de decisión en la vida cotidiana no son resultado de un raciocinio silogístico, como si tuviésemos una tabla de la "verdad" para medir las cosas. Más bien, el actuar resulta de la consideración de innumerables factores, por eso, no hay cómo estimar el comportamiento humano según moldes de racionalidad preestablecida, como parecen creer algunos, pero contra los cuales está la fenomenología, con autores como Edmund HuSSERL y el desdoblamiento de la etnometodología ${ }^{18}$.

En este sentido, una vez identificados los etnométodos de la comunidad jurídica podremos tener informaciones empíricas sobre la práctica de tomas de decisiónes judiciales y, por lo tanto, de cómo los textos legislativos sirven para la búsqueda de inclusión social por medio de los derechos humanos.

Los etnométodos son resultado de la construcción de raciocinios y métodos resultantes de la convivencia social. Es justamente nuestra capacidad de cotidianamente establecer y no establecer (fijar) al mismo tiempo un sentido a lo que vivimos lo que hace posible la comunicación y, por lo tanto, la vida en sociedad. Es lo que deducimos a través de la lectura de autores que hacen referencia a la semántica social ${ }^{19}$. Para LUHMANN, por ejemplo, semántica social es la reserva de reglas de elaboraciones de sentido que permiten la selección de interpretaciones posibles, de modo que funcionen como control para los límites del uso del lenguaje, de manera que garantice la comunicación, así como para controlar el riesgo de la creación de nuevas palabras y expresiones ${ }^{20}$.

En lo cotidiano no cuestionamos cada intención y palabra. Nos comunicamos sin buscar la correspondencia entre un objeto y su signo lingüístico, ni imponiendo un único significado a cada palabra oída. Los significados son construidos según el desarrollo del diálogo o según la convivencia social. Para la etnometodología la comuni-

17 Berger, P. L., y Luckmann, T., 1983: La construcción social de la realidad, Buenos Aires: Amorrotu, p. 57.

18 Coulon, A., 1995: Etnometodologia, Petrópolis: Vozes, p. 12; GARFInKel, H., 1967: Studies in ethnometodology, Cambridge/Oxford: Polity Press, pp. 9-11; HiLBERT, R. A., 1992: The classical roots of ethnomethodology, Durkheim, Weber and Garfinkel. Chapel Hill/London: The University of North California, pp. 56-58.

${ }^{19}$ Luhmann, 1983; Derrida, J., 2002: A escritura e a diferença, São Paulo: Perspectiva; Kristeva, J., 2005: Introdução à semanálise, São Paulo: Perspectiva; TugendHat, E., y Wolf, U., 2005: Propedêutica lógicosemântica, Petrópolis: Vozes; VAN DijK, A., 2000.

20 LUHMANN, 1983: pp. 17-20. 
cación es posible debido a la construcción de sentido producida en el convivir socialmente; o sea, las normas de lo cotidiano son las que permiten la comprensión y la continuidad de la convivencia social ${ }^{21}$.

\section{DISCURSO NORMATIVO Y EMOTIVO PARA LA EFICACIA DE DERECHOS}

Volviendo al ámbito jurídico, consideramos que estamos viviendo un periodo en que las propuestas (ideologías) del positivismo jurídico formalista dogmático no se muestran capaces de relacionar el Derecho con la vida social, o sea, los textos legislativos estatales no sirven como criterios de legitimación. Muchos institutos jurídicos cayeron en descrédito social. Curioso es que no por eso el Derecho puesto por el Estado dejó de ser capaz de servir para la inclusión social y para enfrentarse a la violencia nooficial (como en Max WEBER). Lo que proponemos es que a través de una lectura crítica de las normas jurídicas puestas por el Estado se consigue un camino para poner en marcha institutos jurídicos a favor a la inclusión social, de los derechos humanos.

En el Derecho brasileño, por ejemplo, para que se produzca la condena de los autores de crímenes contra el orden público, como la corrupción y el desvío de dinero público, no es necesaria la creación de un nuevo Derecho, basta aplicar las normas vigentes. Ahora sí llegamos al gran problema, ¿quién decidirá contra actos de la elite, de los dueños del poder? Para eso, más allá de la necesidad de tener coraje meramente para proponer una lectura diversa de la actualmente realizada (la lectura dominante), es necesario el apoyo, por lo menos de parte de la comunidad jurídica.

Eso sí es una dificultad, pues para que ocurra el cambio de lectura es necesario el cambio en los etnométodos, o sea, cambio de la semántica social. Eso exige mucho más que cambios en los textos legislativos. La cuestión, entonces, está en cómo la comunidad jurídica está actuando y para investigarla nuestra propuesta es diagnosticar los etnométodos y la semántica social hoy viva en la comunidad jurídica, para lo cual utilizamos como método cualitativo de encuesta la intertextualidad y la interdiscursividad $^{22}$.

Llama la atención percibir que no hay teorías ni prácticas sociales capaces de ofrecer medios o formas de sustitución de organizaciones sociales como el Estado y sus poderes. Aún se deposita la confianza en el Estado y en sus poderes como medio para promover el orden social. Para combatir las crisis (crisis del Derecho, crisis del poder judicial, crisis de legitimidad), hay muchas doctrinas proponiendo reformas en la legislación y en los medios para optimizar el funcionamiento del Estado, como si fuera suficiente modificar los parámetros formales para transformar la visión de mundo de un pueblo. El problema no es tan simple como desearíamos.

No ignoramos que hay países en los cuales no se puede hablar de lectura diferenciada de las normas jurídicas estatales, pues no tienen un mínimo de legislación que les permitan eso. O sea, en estos países ha de ser iniciada la transformación de

\footnotetext{
21 GARFINKEL, 1967: p. 11.

${ }^{22}$ FAIRCLOUGH, 2001: pp. 112-114; 133-138.
} 
los derechos humanos en derechos fundamentales, para usar la distinción de PÉREZ LuÑO ${ }^{23}$. Pero en muchos otros países, como en Brasil, no hace falta producir nuevos derechos, ni siquiera derechos fundamentales, pues formalmente la Constitución y los códigos los tienen positivados. El problema está más en el no cumplimento de los derechos, así como en la lectura realizada por los tribunales. Eso nos podría llevar al tema de los criterios del nombramiento de los jueces de los tribunales superiores en Brasil, pero en este texto nos basta afirmar que las decisiones de estos tribunales reflejan esa influencia política.

Insistimos, pues, en que la cuestión está en el ámbito de la eficacia, en cómo los agentes jurídicos están leyendo y haciendo uso de los textos de la legislación. Con eso, la relación entre Derecho y política no se establece con la existencia de normas estatales, pues sus textos no son los únicos criterios para la toma de decisión judicial. Tampoco cabe decir que todo es posible con la diferenciación entre reglas y principios. En esos dos casos también hay límites. Repetimos una vez más: debemos evitar la falsa paradoja, decir que no hay una única lectura correcta no significa negar que hay lectura equivocada.

Ya decimos que KeLSEN reconocía la decisión judicial como un acto de voluntad y no como un acto de conocimiento, aun que concibiendo el Derecho como Estado y pretendiendo separarlo de la política. KELSEN, aun con su perspectiva normativista, identificó claramente la presencia de la indeterminación no intencional en el sistema jurídico, como discrecionalidad y presencia de una política del Derecho en la toma de decisiones judiciales ${ }^{24}$.

El debate, por lo tanto, no es nuevo, pero ya que la hermenéutica y el debate entre principio y norma está de moda, trayendo la construcción de principios jurídicos orientadores de todas las ramas del Derecho a partir del texto constitucional ${ }^{25}$, cabe preguntar por qué no investigar los etnométodos y la semántica social de la comunidad jurídica como temáticas de la hermenéutica y de la sociología del Derecho.

Por fin, una sugerencia es la de no limitar el espacio de los derechos humanos a discursos muchas veces "éticos", vacíos de contenido e incapaces de aplicación entre los seres humanos. O sea, recurrir a "frases de efecto" no es eficiente para avanzar en los propósitos de disminuir las diferencias sociales. Ese recurso tiende más bien a dar como resultado un efecto contrario porque produce el alejamiento de posibles adeptos a las causas de los derechos humanos. Produce un diálogo de sordos.

Insistimos en afirmar, para concluir, que no hay ninguna necesidad de creación de nuevos institutos jurídicos para combatir la violencia hoy vivida en todas las partes del mundo. Lo que se precisa es coraje para enfrentar en serio las enfermedades sociales históricamente establecidas. Coraje para leer el Derecho de una forma diferente

23 PÉREZ LuÑO, 1999: p. 31.

24 KeLSEN, 1987: pp. 260-273; 387-397.

${ }^{25}$ Ollero Tasara, A., 1989: Derechos bumanos y metodología juridica, Madrid: Centro de Estudios Constitucionales, p. 231. Aun sobre la metodología en el Derecho: BIX, B., 2003: «Algunas reflexiones sobre metodología en teoría del derecho», DOXA. Cuadernos de filosofía del derecho, n. ${ }^{2}$ 26, pp. 609-633. Para una lectura de la relación derecho y política: WINTGENS, 2003: «Legisprudencia como una nueva teoría de la legislación», DOXA. Cuadernos de filosofía del derecho, n. ${ }^{\circ} 26$, pp. 261-287. 
de la actual. Aquí la paradoja es que, siendo los etnométodos productos del cotidiano, ¿Cómo cambiar los etnométodos de una comunidad? Es lo mismo que preguntar cómo ocurren los cambios sociales. No hay respuesta directa, pero los actores de los cambios sociales son los movimientos sociales.

En relación a la comunidad jurídica ocurre lo mismo, sólo por medio de un movimiento entre los juristas es posible que ocurra un cambio en la semántica social y en los etnométodos. Como sucedió con el movimiento de los jueces italianos cuando la operación manos limpias y hoy, en Brasil con el movimiento contra el nepotismo, el cual afectó a acciones conjuntas de profesionales judiciales del Conselho Nacional de Justiça, Ordem Advogados do Brasil (colegiado de abogados), promotores (fiscales), procuradores da república (abogados publicos) y a Associação dos Juízes para a Democracia (jueces).

Si se entiende por texto la práctica discursiva, la relación entre el discurso y la estructura social se construye «por un lado, en la determinación social del discurso y, por otro, en la construcción del social en el discurso» ${ }^{26}$.

Son los agentes jurídicos quienes definen cómo determinada norma jurídica estatal será aplicada. Por tanto, hay un discurso dominante en la comunidad jurídica. No basta pensar en criticar y denigrar la imagen de los derechos puestos por el Estado, el camino debe ser diverso. Principalmente cuando se entiende que «las personas hacen elecciones sobre el modelo y la estructura de sus oraciones que resultan a su vez en elecciones sobre el significado (y la construcción) de identidades sociales, relaciones sociales y conocimiento y creencias» ${ }^{27}$.

Si en la comunidad jurídica predomina la visión legalista y de que las decisiones resultan sólo de la aplicación de normas estatales, para convivir con esta retórica los defensores de los derechos humanos deben procurar ocupar los espacios en el Derecho estatal para construir una hermenéutica jurídica dirigida a la concreción de los ideales de los derechos humanos. Pero eso exige el trabajo conjunto de abogados, jueces, promotores y procuradores. Eso suena cómodo pero creemos que no se hace revolución con el empleo de la violencia, mucho menos en el mundo jurídico, principalmente porque estamos hablando de cambio racional en la racionalidad judicial.

\section{BIBLIOGRAFÍA}

Alexy, R., 1997: Teoría de los derechos fundamentales, Madrid: Centro de Estudios Constitucionales.

- 2001: Teoria da argumentação jurídica. A teoria do discurso racional como teoria da justificação jurídica, São Paulo: Landy.

ARISTÓTELES, 1973a: «Tópicos», Os pensadores, São Paulo: Abril cultural.

26 Ollero Tasara, A., 1989: p. 92. Sobre un concepto de texto como lenguaje, luego como expresión de la cultura de un pueblo, ver RAJAGOPALAN DERRIDA, K., 2005: Key Thinkers in Linguistics and the Philosophy of Language (orgs. Chapman, S., y Routledge, C.), Reino Unido: Edinburgh University Press, pp. 66-71.

27 Ollero Tasara, 1989: p. 104. 
— 1973b: «Dos argumentos sofísticos», Os pensadores, São Paulo: Abril cultural.

- 1988: «Tópicos», Tratados de lógica (Órganon), vol I, Madrid: Gredos.

BARILli, R., 1979: Retórica. Lisboa: Presença.

BARrY, B., 1997: La justicia como imparcialidad, Barcelona, Buenos Aires, México: Paidós. Berger, P. L., y Luckmann, T., 1983: La construcción social de la realidad, Buenos Aires: Amorrotu.

Bobbio, N., 1933: Teoria generale del diritto, Torino: G. Giappichelli.

CAlvo García, M., 1995: Interpretación y argumentación jurídica, Zaragoza: Prensas Universitarias de Zaragoza.

Correas, O., 1995: Crítica da ideologia jurídica, Ensaio sócio-semiológico, Porto Alegre: SAFE.

Coulon, A., 1995: Etnometodologia, Petrópolis: Vozes.

DerridA, J., 2002: A escritura e a diferença, São Paulo: Perspectiva.

VAN Dijk, T. A., 2000: El discurso como estructura y proceso, Barcelona: Gedisa.

ECO, H., 2004: Interpretação e superinterpretação, São Paulo: Martins Fontes.

EtXeBerRía, X., 1999: «Los Derechos Humanos. Universalidad Tensionada de Particularidad», Los derechos bumanos, camino bacia la paz, Zaragoza: Gobierno de Aragón, pp. 89-105.

FAirclough, N., 2001: Discurso e mudança social, Brasília: UnB.

García Amado, J. A., 1988: Teorías de la tópica jurídica, Madrid: Civitas.

- 2003: Ensayos de filosofía jurídica, Bogotá-Colombia: Temis.

- 2000: «La teoría de la argumentación jurídica: logros y carencias», Sobre el razonamiento jurídico. Revista de ciencias sociales, Facultad de Derecho y Ciencias Sociales. ValparaísoChile: Universidad de Valparaíso, pp. 103-129.

Garfinkel, H., 1967: Studies in ethnometodology, Cambridge/Oxford: Polity Press.

HART, H., 1984/1961: The concept of law, Oxford: Oxford University.

HiLbERT, R. A., 1992: The classical roots of ethnomethodology. Durkbeim, Weber and Garfinkel, Chapel Hill/London: The University of North California.

Kelsen, H., 1987: Teoria pura do direito, São Paulo: Martins Fontes.

Kristeva, J., 2005: Introdução à semanálise, São Paulo: Perspectiva.

Luhmann, N., 1983: Struttura della socetà e semantica, Roma/Bari: Laterza.

- 1985: Come è possible l'ordine sociale, Roma/Bari: Laterza.

- 1990a: Sistemi sociali. Fondamenti di una teoria generale, Bologna: Il Mulino.

- 1990b: La differenziazione del diritto. Contributi alla sociologia e alla teoria del diritto, Bologna: Il Mulino.

- 1997: Organización y decisión. Autopoiesis, acción y entendimento comunicativo, Barcelona/México/Santiago de Chile: Anthropos/Universidad Iberoamericana/Instituto de Sociología. Pontificia Universidad Católica de Chile.

- 2005: El derecho de la sociedad, México: Unversidad Iberoamericana.

Meyer, M., 1993: Questões de retórica. Linguagem, razão e sedução, Lisboa: Edições 70.

Oliveira, L., 1997: «Os Excluídos 'Existem'? Notas sobre a Elaboração de um novo Conceito», Revista Brasileira de Ciências Sociais, n. 33, ano 12, fev., Minas Gerais: ANPOCS, pp. 49-61.

Ollero Tasara, A., 1989: Derechos humanos y metodoloogía jurídica, Madrid: Centro de Estudios Constitucionales.

Perelman, C., 1997: Retóricas, São Paulo: Martins Fontes.

Pérez Luño, A. E., 1999: Derechos humanos, estado de derecho y constitución, Madrid: Tecnos. Possenti, S., 1999: «A lectura errada existe», en BARzotTo, V. H., 1999: Estado da leitura, Campinas: Mercado de Letras, pp. 169-178. 
PlATÓN, 1967: La republica, Madrid: EDFA.

Rajagopalan, K., y DerRIDA, 2005: Key Thinkers in Linguistics and the Philosopby of Language (orgs. Chapman, S., y Routledge, C.). Reino Unido: Edinburgh University Press, pp. 66-71.

Reboul, O., 1998: Introdução à retórica, São Paulo: Martins Fontes.

Rocha, O. A., 1989: «O Advogado Popular e o Judiciário», Direito Insurgente II, Anais da II Reunião LAJUP, S.L.: LAJUP, pp. 43-61.

Stamford Da Silva, A., 2000: Decisão jurídica: dogmatismo e empirismo, Curitiba: Juruá.

Tugendhat, E., y Wolf, U., 2005: Propedêutica lógico-semântica, Petrópolis: Vozes.

VIEHWeg, T., 1986: Tópica y jurisprudencia, Madrid: Taurus.

- 1997: Tópica y filosofía del derecho, Barcelona: Gedisa.

Weber, M., 1996: Economía y sociedad, México: Fondo de Cultura. 